\title{
Coccoid Helicobacter pylori Can Directly Adhere and Invade in Agminated Formation to Human Gastric Epithelial Cells
}

\author{
Nagahito Saito ${ }^{1,2^{*}}$, Hong-Kean $\mathrm{Ooi}^{3^{*}}$, Kohei Konishi ${ }^{2}$, Eriko Shoji ${ }^{2}$, Mototsugu Kato ${ }^{4}$, \\ Masahiro Asaka ${ }^{2}$ \\ ${ }^{1}$ Internal Medicine, Nemuro City Hospital, Nemuro, Japan \\ ${ }^{2}$ Gastroenterology and Hematology Section, Graduate School of Medicine, Hokkaido University, Sapporo, Japan \\ ${ }^{3}$ Veterinary Medicine, National Chung Hsing University, Taichung, Taiwan \\ ${ }^{4}$ Division of Endoscopy, Hokkaido University of Medical Hospital, Sapporo, Japan \\ Email: "nagahitosaito@k7.dion.ne.jp, "hkooi@mail.nchu.edu.tw
}

Received March 7, 2012; revised March 22, 2012; accepted April 5, 2012

\begin{abstract}
Helicobacter pylori (H. pylori) can infect into the epithelial cell to cause benign or malignant disorders. Under stressful environment, a spiral form of $H$. pylori is transformed into a coccoid form. The infectivity of the coccoid form is still controversial. Since spiral forms are transformed into two types of coccoid forms via different mechanisms, the infectivity of the two types of coccoid forms into human gastric epithelial cell was examined. A laboratory and a clinical strain of $H$. pylori were cultured in liquid medium under different conditions to produce the two types of coccoid forms. These coccoid $H$. pyloris were then co-cultured with human derived gastric epithelial cell, MKN-28. Adhesion and penetration of bacteria into MKN-28 cells were monitored by scanning-, standard transmission- and immunotransmission-electron microscopy (SEM, TEM and ITEM). We observed that both coccoid forms were able to adhere onto the surface of MKN-28 cells in agminated formation and also penetrated into the gastric epithelial cells besides the spiral form of $H$. pylori. Coccoid $H$. pylori is not a passive entity but can actively infect the human gastric epithelial cell.
\end{abstract}

Keywords: H. pylori; Electron Microscopy; Coccoid Form; Spiral Form; Bacterial Infection; Cag A

\section{Introduction}

Helicobacter pylori (H. pylori) is a microaerophilic bacterium that produces many benign or malignant disorders [1-3]. Eradication of $H$. pylori in patients after endoscopic resection during the early stage of gastric cancer has been shown to greatly reduce the development of metachronous gastric carcinoma [4]. Under stressful conditions, $H$. pylori changes from a spiral form to a coccoid one [5].

We reported that two types of coccoid forms could be produced in culture using different glucose-concentrations via different mechanisms [6-8]. One form (Type A) has irregular surface with few flagella and an indistinct cytoplasmic membrane cultured in Brucella-specific broth (Difco; USA) culture medium with $10 \%$ heat-activated horse serum (designated as CLM), and the other form (Type B) has smooth surface with tightly encircled flagella and comparatively clear membrane cultured in 300 $\mathrm{mM}$ glucose added CLM (designated as $300 \mathrm{mM}-\mathrm{LM}$ ).

${ }^{*}$ Corresponding authors.
Though the viability and characteristics of the coccoid forms have been a subject of controversy $[9,10]$, there are many reports that non-spiral $H$. pylori is viable and there is a morphological manifestation for cell adaptation to severely non-optimal environment [11].

$H$. pylori can be seen adhering onto the surface of not only the biopsied gastric epithelial cell $[12,13]$ but also cultured cells $[14,15]$. However, there had been several studies on adhesion and invasion of coccoid forms into human epithelial cells. One stated that coccoid forms could adhere and invade into human gastric epithelial cells [16]. Others suggested that coccoid forms could adhere only poorly onto such human cultured cells [17] or that the non-spiral bacteria produced as a result of antibiotic treatment would be passively adhered to such human cultured cells to be eventually destroyed [18].

Therefore, in this study, for the direct observation of the adhesion and invasion of the coccoid $H$. pylori into the epithelial cell, the infectivity of two different types of coccoid forms to human cultured epithelial cells was examined by SEM, TEM and ITEM comparing with that 
of the spiral form as a control. A standard bacterial stock and a clinical strain of $H$. pylori were co-cultured with cells from a human gastric epithelial cell line and then observed by electron microscopy. Some biopsied specimens containing the bacteria and the gastric epithelial cells extracted from the patients with abdominal discomforts were also used as control.

\section{Materials and Methods}

\subsection{Bacterial Culture}

Both the ATCC 43504 strain and a clinical strain established from an $H$. pylori-positive patient were cultured in CLM for 24 hours and then were co-cultured under $8 \%$ $\mathrm{CO}_{2}$ for 1 hour with MKN-28 cells raised in RPMI-1640 medium using a 12 wells plate (Transwell-COL, Corning Costar Co., USA) for 2 days. On the 1st day, approximately $95 \%$ of the bacteria showed spiral forms [6-8].

Both the ATCC 43504 strain and a clinical strain established from an $H$. pylori-positive patient were also cultured in CLM and in 300 mM-LM for 4 days. Organisms on the 4th day culture were used for co-culture with MKN-28 cell to examine the adhesion between bacteria and gastric epithelial cell. On the 4th day, approximately 99\% of the bacteria in CLM was Type A coccoid form and more than $90 \%$ of those in 300 mM-LM was Type B one $[7,8]$.

\subsection{Morphological Preparation}

After discarding the suspended $H$. pylori in the well, the bacteria that adhered to the MKN-23 cell were fixed in a solution containing $0.1 \%$ glutaraldehyde plus $2 \%$ paraformaldehyde. The membrane at the bottom of the well, onto which the cells were attached, was cut into three pieces, each for SEM, TEM and ITEM, respectively, as previously reported. Briefly, for SEM [6] or TEM $[7,8]$, the specimens were fixed in $2 \%$ glutaraldehyde, for observing with an electron microscope. For ITEM $[19,20]$, the fixed specimens were immediately treated with Lowicryl K4M (Polysciences; Tokyo, Japan) followed by ultra-sectioning. Ultrathin sections mounted on nickel grids were reacted with a rabbit IgG fraction specific for $H$. pylori (DAKO Japan) followed by reacting with gold particle-labeled goat antiserum specific for rabbit IgG. Biopsy materials from the gastric antrum of 24 patients examined by endoscopy for dyspepsia symptoms were also processed by the standard procedure for SEM, TEM and ITEM. No malignant lesion was diagnosed in all biopsy materials by standard light micros-copy.

\section{Results}

By ITEM, the gold particles indicating positive reaction for the presence of $H$. pylori antigen were detected on the flagella, on the bacterial surface and in the cytoplasm of the bacteria. Our electron microscopic study showed that $H$. pylori bacteria first aligned in agminated pattern to adhere onto the surface of epithelial cell to be incorporated into the cytoplasm.

In the SEM study using spiral bacteria, the gastric epithelial cell was adhered onto the surface by the bacteria in agminated pattern (Figure 1(a)). By TEM and
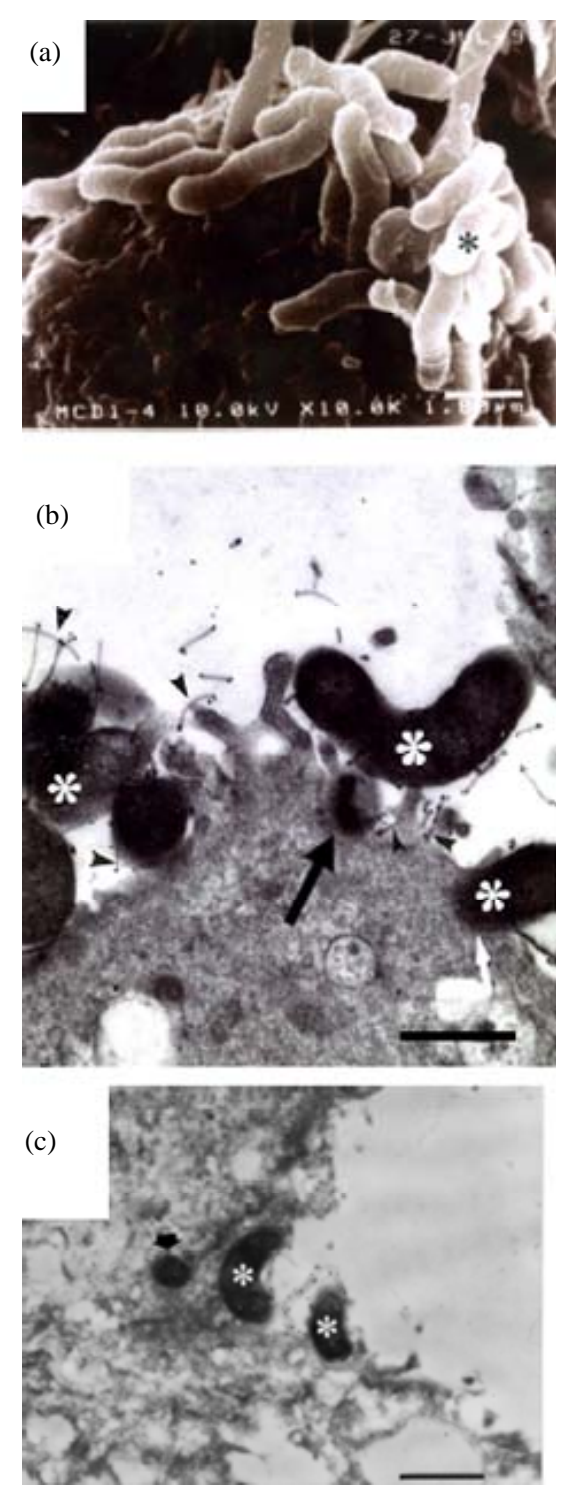

Figure 1. Spiral $H$. pylori as controls. (a) The bacterium (asterisk) agminates onto a certain spot of the surface of the epithelial cell (SEM: A clinical strain from the 1st day of culture. Bar indicates $1 \mu \mathrm{m}$ ); (b) The bacterial body (asterisks) directly attaches or is taken (black and white arrows) into the epithelial cell. Flagella (arrowheads) also adhere on the epithelial cell (TEM: ATCC43504 strain from the 1st day of culture, Bar indicates $0.5 \mu \mathrm{m}$ ); (c) The bacteria (asterisks) directly agminate to contact on the surface of the epithelial cell. A bacterial body (arrow) is observed in the cytoplasm (ITEM: A biopsy specimen, Bar indicates $1 \mu \mathrm{m}$ ). 
ITEM, spiral bacteria were observed to be directly in close contact with the surface or microvilli of the epithelial cells (Figures 1(b) and (c), asterisks) with flagella touching the microvilli (Figure 1(b), arrowheads) and also their body being already in the cytoplasm of the epithelial cell (Figures 1(b) and (c), arrow). We could not observe any agminated pattern of $H$. pylori on any of the biopsied specimens by SEM. Type A (Figures 2(a)(c)) and Type B (Figures 2(d) and (e)) coccoid bacteria from the standard bacterial stock and a clinical strain of $H$. pylori adhered in similar manner to that of the spiral form. In Type A coccoid forms, the spherical bacteria were seen adhering in agminated pattern on the surface of the epithelial cells (Figure 2(a)). Remnants of the flagella and the bacterial body were seen to be directly in contact with the surface of the epithelial cells (Figure 2(b), arrowheads). A vacuole as indicated by gold particles was considered to be the existence of the invaded bacteria in the cytoplasm (Figure 2(c), arrow). Type B coccoid forms also adhered in agminated pattern on the surface of the epithelial cells (Figure 2(d)). Flagella (Figure 2(e), arrowheads) and the bacterial body (Figures 2(b) and (c), asterisks) were observed to be directly in contact with the surface of the epithelial cells. Amorphous structure with gold particles showing the presence of $H$. pylori antigen in the cytoplasm of the infected epithelial cells (Figures 2(c) and (e), arrow) demonstrated that the adhered bacterium had been taken into the epithelial cell.

\section{Discussion}

In this study, we observed that not only the spiral $H$. pylori but also the coccoid ones assembled at a certain area on the surface of the epithelial cell before being taken into the cytoplasm. In general, a bacterium is thought to adhere to and invade into the epithelial cell only after the colony formation by its own cell-fission [21]. However, our study showed that many coccoid bacteria adhered simultaneously in a convergent fashion onto a narrow area on the surface of the epithelial cell and then invaded into the cytoplasm. In several biopsy specimens, we also observed the internalization of the agminated organisms by TEM and ITEM. In studies using cultured HEp-2 [14, 22] or AGS [23] cells, only spiral $H$. pylori has been reported to be taken into those cells. However, our study
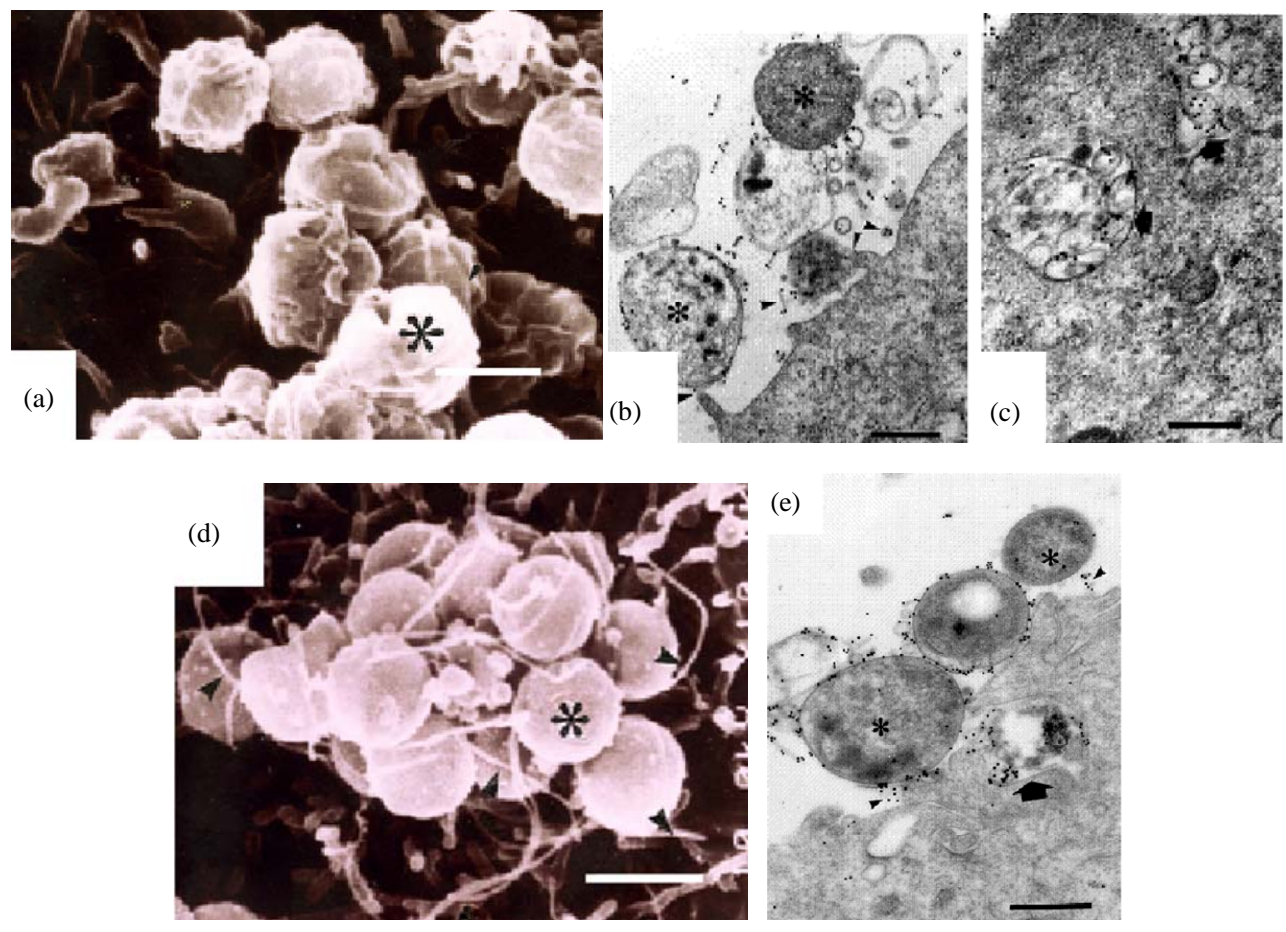

Figure 2. Coccoid $H$. pylori invasion into gastric epithelial cells (Bar indicates $0.5 \mu \mathrm{m})$. (a)-(c) show ATCC43504 strain from the 4th day in CLM. (a) Type A coccoid forms (asterisk) also agminates onto a certain area in similar way as shown by the spiral ones serving as control (SEM); (b) Type A coccoid forms (asterisks) are directly in contact with the surface of the epithelial cells using fragella and the bodies (arrowheads) (ITEM); (c) The anti-H. pylori antibody positive structures (arrows) are observed in the cytoplasm of the epithelial cells indicating successful penetration (ITEM); (d) and (e) show ATCC43504 strain from the 4th day in $300 \mathrm{mM}-\mathrm{LM}$; (d) Type B coccoid forms (asterisks) also agminates onto a certain area as the spiral and coccoid A bacteria. (SEM); (e) Type B coccoid forms (asterisks) directly in contact with the epithelial cells in the same way as the type A coccoid ones (ITEM) Anti-H. pylori antibody positive flagella (arrowheads) are seen. Anti-H. pylori antibody positive structure (arrow) is seen in the cytoplasm of epithelial cell. 
using Type A- and Type B-coccoid H. pylori in vitro [6$8,19]$ showed colony-like formation with attaching by themselves and invading into the epithelial cells, like that seen for the spiral form.

We have already reported that coccoid $H$. pylori is divided into four categories, namely, the dying one, the living one with culturability, the viable but non-culturable one and a special form prepared for species-preservation [19]. In this study, we could observe that the adhered coccoid forms showed an agminated pattern converging at a certain site and then penetrated into the gastric epithelial cells. From this observation, we propose the existence of a fifth category of coccoid $H$. pylori, one which can aggressively adhere in agminated manner and infuse their own genes into the cytoplasm of epithelial cells just like those of the spiral forms. Finally, the genes of the coccoid $H$. pylori could be involved in the production of human gastric ulcers, cancers and other diseases after the invasion into the epithelial cell.

From our observation, whole genes of coccoid $H$. pylori appeared to be finally incorporated into the epithelial cells. It is well-known that this bacterium also elicits many benign disorders such as coronary heart disease [2] or idiopathic thrombocytopenia [24] other than gastric carcinoma. Moreover, almost all Japanese patients with peptic ulcer, who are infected by Cag A-positive $H$. pylori [25], do not develop further to duodenal cancer [26]. From this clinical observation, it is suggested that several different genes other than Cag A are simultaneously taken into the epithelial cell and are transported together with Cag A to play their own respective roles in the mutation of the human cell. Since the infection of $H$. pylori into the gastric epithelial cells is facilitated through direct contact between the cells, several genes from the agminated bacteria will be transferred into human gastric epithelial cell leading to their transformation in accordance to the immunological status vis-a-vis between the bacteria and the host cell.

We actually observed that a transgenic epithelial cell being inserted with just Cag A gene gave rise to ultrastructural changes, but did not ultimately led to the direct onset of oncogenesis. We observed the presence of glycogen clusters and increased in the bundles of actin filaments, in the Cag A inserted transgenic epithelial cell (not shown in detail here. In preparation for a paper). Thus, it is suggested that the malignant transformation of gastric epithelial cell would need the interaction of several other genes, rather than just Cag A. This study supports the clinical phenomena that all other genes attached together with $\mathrm{Cag} A$ are simultaneously taken into epithelial cells resulting in several disorders. Furthermore, coccoid $H$. pylori, while trying to adapt to the harsh environment, would probably also elicit several $H$. pylorirelated disorders.
Since several biopsied specimens showed agminated and invading bacteria, we raised an alarm that these patients should be given due attention for the treatment of sporadic $H$. pylori-related disorders because the bacterial genes might have been inserted into their gastric epithetlial cells. Thus, our study demonstrated that coccoid $H$. pylori is not a passive entity but can actively infect into the human gastric epithelial cell.

In conclusion, from this study, we proposed that coccoid $H$. pylori possessed a fifth characteristic; the ability to directly infect into gastric epithelial cells. This will be added to the already known 4 categories, viz, the dying one, the living one with culturability, the viable but nonculturable one and the active form for species-preservation.

\section{REFERENCES}

[1] M. Asaka, T. Kimura, M. Kato, M. Kudo, K. Miki, K. Ogashi, T. Kato, M. Tatsuta and D. Y. Graham, "Possible Role of Helicobacter pylori Infection in Early Gastric Cancer Development," Cancer, Vol. 73, No. 11, 1994, pp. 2691-2694.

doi:10.1002/1097-0142(19940601)73:11<2691::AID-CN CR2820731107>3.0.CO;2-2

[2] M. A. Mendall, P. M. Goggin, N. Molineax, J. Levy, T. Toosy, D. Strachen, A. J. Camm and T. C. Northfield, "Relation of Helicobacter pylori Infection and Coronary Heart Disease,” British Heart Journal, Vol. 71, No. 5, 1994, pp. 437-439. doi:10.1136/hrt.71.5.437

[3] R. Calvert, J. Randerson, P. Evans, L. Cawkwell, F. Lewis, M. F. Dixon, A. Jack, R. Owen, C. Shiach and G. J. Morgan, "Genetic Abnormalities during Transition from $\mathrm{He}$ licobacter-pylori-Associated Gastritis to Low-Grade MALToma,” Lancet, Vol. 345, No. 8941, 1995, pp. 26-27. doi:10.1016/S0140-6736(95)91154-5

[4] K. Fukase, M. Kato, S. Kikuchi, K. Inoue, N. Uemura, S. Okamoto, S. Terao, K. Amagai, S. Hayashi and M. Asaka, "Effect of Eradication of Helicobacter pylori on Incidence of Metachronous Gastric Carcinoma after Endoscopic Resection of Early Gzstric Cancer: An Open-Label, Randomized Controlled Trial,” Lancet, Vol. 372, No. 9636, 2008, pp. 392-397. doi:10.1016/S0140-6736(08)61159-9

[5] M. Wen, N. Yamada, Y. Zhang and T. Matsuhisa, "Morphological Changes of Helicobacter pylori after Antibacterial Therapy: An Electron Microscope Study,” Medical Electron Microscopy, Vol. 30, No. 3, 1997, pp. 131-137. doi:10.1007/BF01545314

[6] F. Sato, "Helicobacter pylori in Culture: An Ultrastructural Srudy," Hokkaido Journal of Medical Science, Vol. 75, No. 3, 2000, pp. 187-196.

[7] F. Sato, N. Saito, K. Konishi, E. Shoji, M. Kato, H. Takeda, T. Sugiyama and M. Asaka, "Ultrastructural Observation of Helicobacter pylori in Glucose-Supplemented Culture Media,” Journal of Medical Microbiology, Vol. 52, No. 8, 2003, pp. 675-679. doi:10.1099/jmm.0.05146-0 
[8] N. Saito, K. Konishi, F. Sato, M. Kato, H. Takeda, T. Sugiyama and M. Asaka, "Plural Transformation-Processes from Spiral to Coccoid Helicobacter pylori and Its Viability,” Journal of Infection, Vol. 46, No. 1, 2003, pp. 49-55. doi:10.1053/jinf.2002.1047

[9] M. Benaissa, P. Babin, N. Quellard, L. Pezennec, Y. Cenatiempo and J. L. Fauchere, "Changes in Helicobacter pylori Ultrastructure and Antigens during Conversion from the Bacillary to the Coccoid Form," Infection and Immunity, Vol. 64, No. 6, 1996, pp. 2331-2335.

[10] J. G. Kusters, M. M. Gerrits, J. A. G. Van Strijp and C. M. J. E. Vandenbroucke-Grauls, "Coccoid Forms of Helicobacter pylori Are the Morphologic Manifestation of Cell Death," Infection and Immunity, Vol. 65, No. 9, 1997, pp. 3672-3679.

[11] N. F. Azevedo, C. Almeida, L. Cerqueira, S. Dias, C. W. Keevil and M. J. Vieira, “ Coccoid form of Helicobacter pylori as a Morphological Manifestation of Cell Adaptation to the Environment," Applied and Environmental Microbiology, Vol. 73, No. 10, 2007, pp. 3423-3427. doi:10.1128/AEM.00047-07

[12] S. J. Hessey, J. Spencer, J. I. Wyatt, G. Sobala, B. J. Rathbone, A. T. R. Axon and M. F. Dixon, "Bacterial Adhesion and Disease Activity in Helicobacter Associated Chronic Gastritis,” Gut, Vol. 31, No. 2, 1990, pp. 134-138. doi:10.1136/gut.31.2.134

[13] N. Saito, F. Sato, H. Oda, M. Kato, H. Takeda, T. Sugiyama and M. Asaka, "Removal of Mucus for Ultrastructural Observation of the Surface of Human Gastric Epithelium Using Pronase," Helocobacter, Vol. 7, No. 2, 2002, pp. 112-115. doi:10.1046/j.1083-4389.2002.00070.x

[14] D. G. Evans, D. J. Evans Jr. and D. Y. Graham, “Adherence and Internalization of Helicobacter pylori by HEp-2 Cells,” Gastroenterology, Vol. 102, No. 5, 1992, pp. 15571567.

[15] U. Heczko, V. C. Smith, R. M. Meloche, A. M. J. Buchan and B. B. Finlay, "Characteristics of Helicobacter pylori Attachment to Human Primary Antral Epithelial Cells," Microbes and Infection, Vol. 2, No. 14, 2000, pp. 16691676. doi:10.1016/S1286-4579(00)01322-8

[16] Z.-F. Liu, C.-Y. Chen, W. Tang, J.-Y. Zhang, Y.-Q. Gong and J.-H. Jia, "Gene-Expression Profiles in Gastric Epithelial Cells Stimulated with Spiral and Coccoid Helicobacter pylori," Journal of Medical Microbiology, Vol. 55, No. 8, 2006, pp. 1009-1015. doi:10.1099/jmm.0.46456-0

[17] S. P. Cole, D. Cirillo, M. F. Kagnoff, D. G. Guiney and L. Eckmann, "Coccoid and Spiral Helicobacter pylori Differ in Their Abilities to Adhere to Gastric Epithelial Cells and Induce Interleukin-8 Secretion," Infection and Immunity, Vol. 65, No. 2, 1997, pp. 843-846.

[18] Y.-T. Chu, Y.-H. Wang, J.-J. Wu and H.-Y. Lei, "Invasion and Multiplication of Helicobacter pylori in Gastric Epithelial Cells and Implications for Antibiotic Resistance," Infection and Immunity, Vol. 78, No. 10, 2010, pp. 4157-4165. doi:10.1128/IAI.00524-10

[19] N. Saito, K. Konishi, H. Takeda, M. Asaka and H. K. Ooi, "Coccoid Formation as a Mechanism of Species-Preservation in Helicobacter pylori: An Ultrastructural Study," Hokkaido Journal of Medical Science, Vol. 83, No. 5, 2008, pp. 291-295.

[20] N. Saito, K. Konishi, H. T. akeda, M. Kato, T. Sugiyama and M. Asaka, “Antigen Retrieval Trial for Post-Embedding Immunoelectron Microscopy by Heating with Several Unmasking Solutions," Journal of Hisochemistry and Cytochemistry, Vol. 51, No. 8, 2003, pp. 989-994. doi:10.1177/002215540305100802

[21] K. Amako and Y. Minamishima, Eds., “Toda’s 'New Bacterioligy’,” 31st Edition, Nanzando Company Ltd., Tokyo, 1997, pp. 195-212.

[22] S. W. Wilkinson, J. R. Uhl, B. C. Kline and F. R. Cockerill III, “Assessment of Invasion Frequencies of Cultured HEp-2 Cells by Clinical Isolates of Helicobacter pylori Using an Acridine Orange Assay,” Journal of Clinical Pathology, Vol. 51, No. 2, 1998, pp. 127-133. doi:10.1136/jcp.51.2.127

[23] E. D. Segal, S. Falkow and L. S. Tompkins, "Helicobacter pylori Attachment to Gastric Cells Induces Cytoskeletal Rearrangements and Tyrosine Phosphorylation of Host Cell Proteins," Proceedings of the National Academy of Sciences of the United States of America, Vol. 93, No. 3, 1996, pp. 1259-1264. doi:10.1073/pnas.93.3.1259

[24] K. Fujimura, "Helicobacter pylori Infection and Idiopathic Thrombocytopenic Purpura,” International Journal of Hematology, Vol. 81, No. 2, 2005, pp. 113-118. doi:10.1532/IJH97.04161

[25] M. Hatakeyama and H. Higashi, "Helicobacter pylori Cag A: A New Paradigm for Bacterial Carcinogenesis," Cancer Science, Vol. 96, No. 12, 2005, pp. 835-843. doi:10.1111/j.1349-7006.2005.00130.x

[26] T. Sugiyama, K. Nishikawa, Y. omatsu, J. Ushizuka, T. Mizushima, A. Kumagai, M. Kato, N. Saito, H. Takeda, M. Asaka and J. W. Freston, "Attributable Risk of $H$. pylori in Peptic Ulcer Disease,” Digestive Diseases and Sciences, Vol. 46, No. 2, 2001, pp. 307-310. doi:10.1023/A:1005600831851 